\title{
Methods of estimating the effects of heterosis
}

\author{
E. FIMLAND \\ N.R.F., Departement of Animal Genetics and Breeding \\ Agricultural University of Norway, $\stackrel{\circ}{A}-\mathrm{NLH}$, Norway
}

The present paper describes a general linear model for obtaining fixed parameters in crossbreeding experiments. The principle of minimum average square error is used for choosing the "best» model for prediction. The effect of ignoring some parameters in general is given. Application of the model to different types of crossbreeding experiment is discussed. In this connection, the estimability of the parameters is shown.

Some general comments are given on which type of mating that should be prefered with fixed testing capacity.

\section{Theoretical aspects of different crossbreeding structures}

\author{
E.P. CUNNINGHAM \\ The Agricultural Institute, Dublin 4, Ireland
}

Crossbreeding systems are used to exploit heterosis, or complementarity, or both. Judging from experimental results, the simple dominance model of heterosis appears to be reasonably adequate. However, in particular cases, the applicability of the model may be affected by the genetic nature and structure of the population, and by the possible dependence of heterosis on environmental level.

Assuming heterosis is a linear function of heterozygosity, any particular crossbreeding strategy can be evaluated in terms of the degree of heterozygosity which it preserves, and in terms of the balance of genes which it maintains from the separate components. Several strategies are examined in this way.

The final point made is that crossbreeding is not an alternative to selection, but in every case must lead to or be supported by a selection programme.

\section{Heterosis effects in Fleckvieh-Pinzgauer crosses}

\author{
R. GRAML and F. PIRCHNER \\ Lehrstuhl für Tierzucht, der Technischen Universität \\ München, Freising-Weihenstephan, Bundesrepublik Deutschland
}

Sixty German Fleckvieh $\times$ Pinzgauer $F_{1}$ and $R_{1}$ crossbreds were used to estimate heterosis effects. All investigated traits, age at first calving, calving interval, milk and butterfat yield, both for 90 days records and for complete first lactations showed heterosis. Three additional crosses $(\mathrm{FV} \times \mathrm{BV}, \mathrm{FV} \times \mathrm{SB}, \mathrm{Pi} \times \mathrm{SB}$ ) were used to relate heterosis to genetic distance estimated from marker genes and to absolute yield difference of parental breeds. The heterosis is nearly linearly dependent on the absolute yield difference. The relation with the marker distance is less marked, however, it is not negligible. 